\title{
Short film production in educational contexts: Exploring the methodology of the Olhar pela Lente project in Portugal
}

Pedro Alves (iD and Ana Sofia Pereira (D)

\section{How to cite this article}

Alves, P. and Pereira, A.S. (2020) 'Short film production in educational contexts: Exploring the methodology of the Olhar pela Lente project in Portugal'. Film Education Journal, 3 (1), 13-31. https://doi.org/10.14324/FEJ.03.1.02

Submission date: 3 September 2019

Acceptance date: 31 January 2020

Publication date: 23 June 2020

\section{Peer review}

This article has been peer reviewed through the journal's standard double-blind peer review, where both the reviewers and authors are anonymized during review.

\section{Copyright}

(C) 2020 Alves and Pereira. This is an Open Access article distributed under the terms of the Creative Commons Attribution Licence (CC BY) 4.0 https://creativecommons.org/licenses/ by $/ 4.0 /$, which permits unrestricted use, distribution and reproduction in any medium, provided the original author and source are credited.

\section{Open access}

The Film Education Journal is a peer-reviewed open-access journal. 


\title{
Short film production in educational contexts: Exploring the methodology of the Olhar pela Lente project in Portugal
}

\author{
Pedro Alves* - Catholic University of Portugal \\ Ana Sofia Pereira - NOVA University of Lisbon, Portugal
}

\begin{abstract}
Cinema's pedagogical essence nurtures a variety of educational strategies. Beyond serving as a support to other areas of knowledge or as the subject of artistic analysis, it also provides students with a means to give - freely and significantly - voice to their own concerns and interests. Short film production in schools can offer a process for young people to deal with personal and social challenges, fostering a closer connection between them and their community and environment. Schools are natural habitats for this encounter - a place where film production can generate significant educational and cultural resonance. This paper reflects on the didactic potential of short film production in schools - as a key to fulfil formal and non-formal pedagogical goals - through the presentation and analysis of a recently implemented methodology for education through film: Olhar pela Lente, a project developed in Portugal during 2018.
\end{abstract}

Keywords: film education; short film production; methodology; school; Olhar pela Lente

\section{Introduction}

In 2017, ESVV (Secondary School of Vila Verde - a Portuguese village in the district of Braga, in the north of Portugal), together with the local city council and the Intermunicipal Community of Cávado, applied successfully for Europe 2020 funds with an Integrated and Innovative Plan to Combat School Underachievement (IIPCSU). Mirroring ESVV's mission, IIPCSU aimed to improve students' school results, and raise their behavioural, motivational and cultural standards, as well as to offer them equal opportunities and quality training (ESWV, 2016) through contact with different forms of art. One of the chosen artistic fields was film, through a project called Olhar pela Lente $(\mathrm{OPL})$ - in English, 'Look through the lens'. OPL's main goals were: to stimulate student reflection on film history and film's role within wider society; to recognize film as a cultural and artistic expression; and to develop film literacy, aesthetic sensibility and critical thinking (ESV, 2017) through short film production. Europe 2020 funds enabled the school to be equipped with video cameras, lenses, tripods, sliders, lighting kits and reflectors, and microphones - all to be used exclusively within the scope of the project. OPL set out to involve five ESV teachers and 160 tenth graders (15-16 year olds) from seven non-artistic regular and professional education classes (two in humanities, and one each in accounting, informatics, psychosocial, health and tourism).

We were asked to design and implement the project's methodology, as external film tutors who would work with the assigned ESWV teachers and students. Our main 
question was: how can we use short film production and film literacy to foster students' motivation, engagement and productivity in terms of their relationship with their school and their wider sociocultural environment? This led us to explore the pedagogical relevance of narrative films and different film education strategies in order to frame OPL's rationale, design and empirical implementation in the first semester of 2018, which we analyse and discuss below.

\section{Why film narratives?}

Narrative thinking may be considered unavoidable in the knowledge and meaning developed from the experience of reality. Narrative schemas constitute acts of coherence and significant resolution in the critical assimilation of information from the chaos of the real (Robinson and Hawpe, 1986:111-12). In this sense, stories are naturally didactic. Knowledge is developed and organized to a large extent by the stories we tell and hear, and these have a significant impact upon our own empowerment within and towards reality (Plummer, 2019). This motivation to tell and receive narratives arises not only for the purpose of entertainment, but also due to the fundamental will and need to construct coherent and plausible perspectives on reality, on others and on ourselves (Schank and Berman, 2002: 288-9). Moreover, a story reflects the feelings, ideologies or goals of its creator, providing a vehicle for representing different perspectives on the world. Every story is dependent on the subject who creates it and the subject who receives it (Strange, 2002: 282). This highlights the relevance of narrative for ESVV's mission and OPL's goals, because narrative triggers in young people a significant knowledge of themselves, their peers and their sociocultural reality, from a creative and critical standpoint.

Furthermore, film has been situated as a fundamental field for the cultural experience (individual and collective) of human beings in general. Through a strong sensorial impact, film stimulates narrative and fiction as 'laboratories of life itself' (García García and Rajas, 2011: 10), leading spectators to be immersed in new forms of experience and knowledge that can transform and expand their reality. Within a playful context, free from the worries of the physical world, film allows human beings to experience things that amplify or surpass reality and the opportunities it offers (Plantinga, 2009: 67). For that reason, film also possesses an intrinsic didactic quality that, primarily, stems from its non-formal scope of experimentation (Alves, 2015), but quickly overflows into the broad potential of formal pedagogical use. Schools are the most privileged and relevant spaces for this, because they act as 'decisive actors' and natural meeting points for students and film (Lardoux, 2014: 18). Countless children and adolescents would have significantly limited contact with film (in terms of both quantity and quality of films viewed) if not for film activities taking place in schools (Bergala, 2007: 36). It is through the inclusion of film in the curricular and extra-curricular programmes of schools that young people have a more democratic access to the cinematographic experience, something that contributes to expanding their cultural horizons and their critical and aesthetic abilities (Aidelman and Colell, 2018).

\section{Short film production in educational contexts: Why and how?}

Two possible uses of film in didactic contexts are: its instrumentalized use within other curricular subjects (learning with film), and its textual and/or formal analysis as the main pedagogical focus (learning film). In both variants, film allows for a vivid 
experimentation in interpreting events and narratives closely linked to certain curricular goals and/or contents (Gispert Pellicer, 2009). Several studies and models have been proposed, tested and analysed for these two methods of didactic film usage (García Amilburu and Landeros Cervantes, 2011; Vaccaro and Valero, 2011; Baptista Neves, 2013; Reigada, 2016; Reia-Baptista et al., 2014; BFI, 2011).

Another possible use of film within schools - and the one that interested us the most with OPL - is learning through film's creative process. One of the starting points for OPL's rationale was the British Film Institute's (BFI) A Framework for Film Education report (2015). Focusing on the educational role of film among children and young people, the document proposes that schools should offer 'experimentation, learning and appreciation' (BFI, 2015: 3) of film. It defines core learning objectives, such as understanding film as a collective and collaborative production; establishing critical, aesthetic, emotional, cultural and creative perspectives through film works; and developing a social, cultural and historical awareness of film (ibid.). It also establishes three key dimensions in young people's film awareness, which influenced the formulation of OPL's rationale, methodology and design: a critical dimension (to develop a reflexive ability, and to understand film in its aesthetic, narrative, technical and semiotic variety); a creative dimension (autonomous expression of individuality, from an idea, a world view and a critical, technical and/or intellectual capacity); and a cultural dimension (understanding film as the possibility for personal and collective identities, values, ideas and encounters). These dimensions and their implications are summarized in Figure 1.

\section{FILM EDUCATION FRAMEWORK FOR EUROPE}

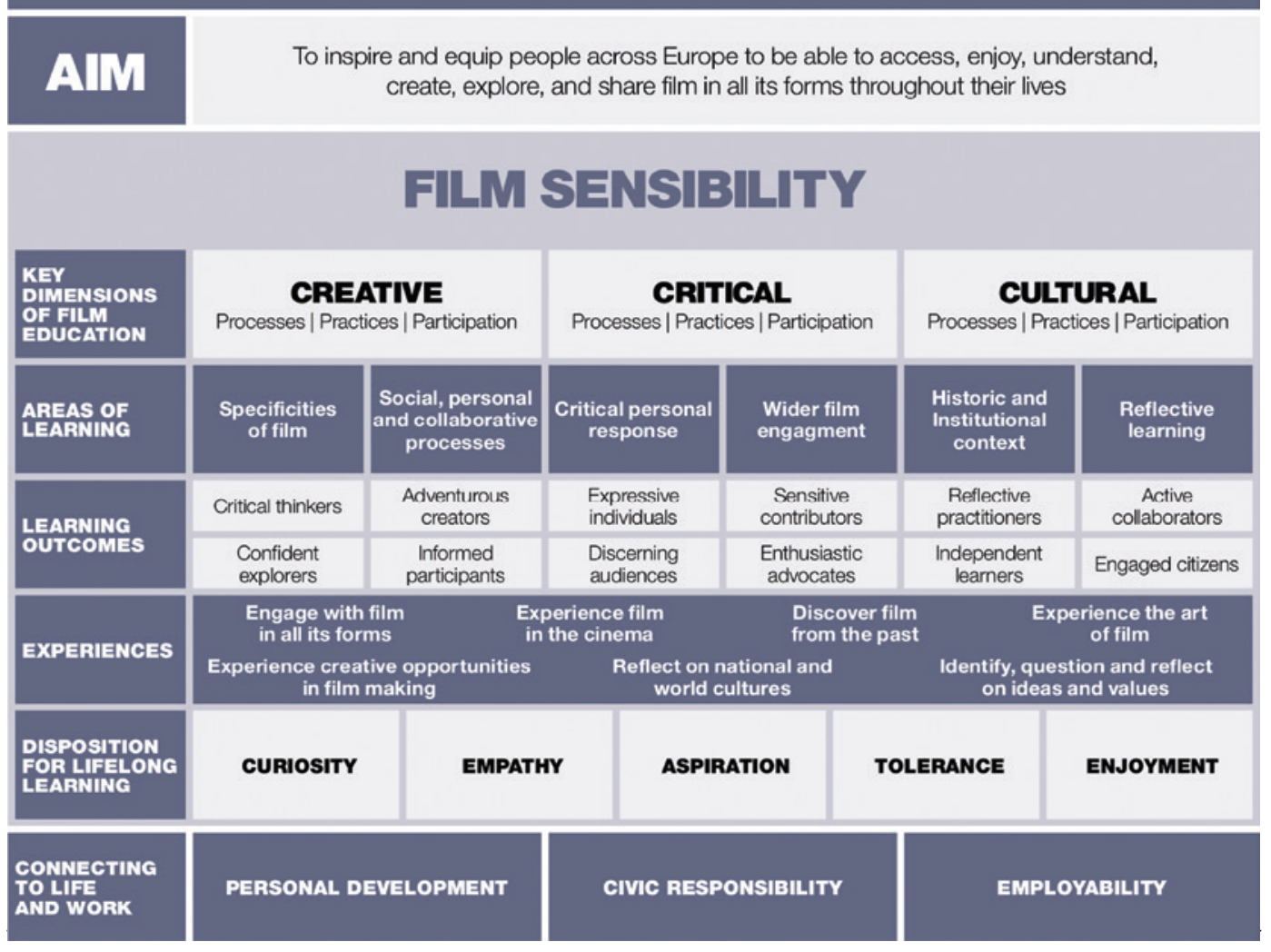

Source: BFI (2015: 7)

Figure 1: Film education framework for Europe 
The BFI's framework dimensions, learning areas and outcomes, experiences, and connections to life and work inspired the main features of our approach with OPL: an unforeseeable and subjective process, favouring educational experiences that call upon students' subjectivity as raw material for the works accomplished (Rodríguez Hoyos and Manrique Solana, 2015: 115). This kind of education through film we argue fosters students' motivation and engagement with their school environment, as it allows them to incorporate their own profile into both the process and the final product, combining two fundamental strands of their development: the recreational and the social (Lazo and Gabelas Barroso, 2012).

Film creation also entails non-formal educational challenges, such as managing space, time and resources. Students are required to make decisions (what and how to shoot), and to articulate the notions of narrative and shooting time, as well as to adapt their intentions and vision to the shooting conditions and limitations. Thus, students evolve in terms of the quantity and quality of their decisions, as it is 'extremely important ... that each individual student is confronted at least once with the full and total responsibility of a creative gesture, with all it involves regarding choice, spirit of decision, bet, emotion and fear' (Bergala, 2007: 198). This is particularly relevant in two interesting projects involving the Portuguese organization Os Filhos de Lumière, both of which represent important references for OPL's rationale and design: $O$ Primeiro Olhar (a film initiation workshop mentored by professionals that aims to assist young people in discovering film language and mastering basic skills and film crafts, such as image, sound and editing); and Moving Cinema (a Creative Europe project involving five countries, which directs film screenings, film theory and film analysis towards short film production experiences using mobile devices).

Film production also entails a process of collective sense-making, where individuals gather to form a collaborative body, autonomously responsible for personal and group decisions. Often this 'joint voice' can help to reposition and stimulate students whose prior educational or social experiences have been adverse, allowing them space for confidence-boosting responsibilities and tasks (Bergala, 2007: 195). Hence, learning through film production helps students develop not only critical thinking but also aspects of emotional intelligence (Bergala, 2007: 175). We wanted to make the most of these potential aspects of film education with $\mathrm{OPL}$, in directing collective effort towards a creative project in order to foster integration, motivation, well-being and personal and social development.

Regarding the teacher's role in this process, a degree of proficiency in the subject being taught is important. Only in this way will students' interest in the subject be aroused, stimulating their will to learn, and directing their efforts towards the defined objectives (García Amilburu and Landeros Cervantes, 2011: 31-2). However, it is important that the teacher does not impose himself or herself on the creative work of the student, but participates as a mediator and facilitator of a work that must arise from the student's responsibility and authorship (Bergala, 2007: 171-2). Therefore, we needed to involve ESW teachers as active actors in OPL - on the one hand, facilitating the development of film literacy tools and film production skills with young people, while on the other hand, making teachers aware of the need to privilege the creative freedom and autonomy of their students.

Another important (and recurrent) aspect of the relevance and specificity of film education is the primacy of the process over the achieved result. For OPL's methodology design, it seemed to us that we should value 'the implication in the process, the coherence of this process, the fact that the student has made real choices and has been tested against the reality of the shooting and editing' (Bergala, 2007: 169), over 
the final product. This is an approach to film education that a project such as 'Cinéma, cent ans de jeunesse' (one of the most significant contemporary references for any kind of educational intervention with or through film) has always strongly defended. More than the intelligibility or quality of the films, the experience of cinematic creation must contribute to the development of two different sets of skills and knowledge: those relevant to the school, and those important to the sociocultural development of young people. Students must engage with the film production process, developing their intelligence, their sensitivity and their decision-making through the processes and language inherent in film expression. Hence, we consider this kind of education through film to be an efficient means to help develop new audiences (for film and culture) and new citizens, formed not only by contemplation-fuelled dialogue, but also by the commitment to common causes and collective efforts (Babo, 2015: 29).

This theoretical and empirical scope defined the major guidelines for OPL's methodology. We aimed for a programme combining film theory, film analysis and film practice, providing conditions for the application of filmic - but also individual, social, artistic and cultural - knowledge and skills in the process of cinematic creation. We wanted to address the major concerns and goals of IIPCSU through a student-oriented project, where tutors and teachers participated as mediators and facilitators of film literacy and expression. We intended to provide a space for students' creativity, and their critical and cultural implication and participation, fostering their subjective world views, interests and challenges as the privileged raw material to use in film creation.

\section{Olhar pela Lente: Methodology and analysis}

OPL entailed 16 weeks of work with the 160 students involved. These were distributed in seven classes, and each class was allocated 90 minutes per week for participating in the sessions with the film tutors. This meant a total of 24 face-to-face hours with

Table 1: Distribution of contents throughout the 16 weeks of OPL

\begin{tabular}{|l|l|}
\hline Week & Content \\
\hline 1 & Presentation: Introduction to film practice \\
\hline 2 & Concepts of film narrative \\
\hline 3 & Narrative idea and characters \\
\hline 4 & Film structure and step-outline \\
\hline 5 & Screenwriting \\
\hline 6 & Screenwriting; final revisions \\
\hline 7 & Pre-production \\
\hline 8 & Image, lighting and sound \\
\hline 9 & Film production exercise \\
\hline 10 & Image and sound tests; closing pre-production \\
\hline 11 & Film shooting \\
\hline 12 & Film shooting (and editing) \\
\hline 13 & Film shooting (and editing) \\
\hline 14 & Editing \\
\hline 15 & Editing \\
\hline 16 & Short film presentation at Vila Verde's Centre for Arts and Culture \\
\hline
\end{tabular}


each class, which represents relatively little time to develop, deeply and meaningfully, the process of producing a short film with students, an aspect of the project that we later found led to aspects of difficulty. Thus, we had to address and discuss filmrelated knowledge and skills initially through a rather basic approach, in order not to overwhelm students' ability to comprehend the content and processes.

The distribution of content and activities during these 16 weeks sought a balance between theoretical and practical approaches, and followed the natural progression of the different phases of a professional film production (see Table 1). The intention was, on the one hand, to emphasize the need for students' autonomy, responsibility and decision-making at every stage of the learning process, while, on the other hand, promoting their sense of developing a project of their own, from start to finish, highlighting the relevance of their own subjectivities and interests in this process. Furthermore, it involved exhibiting the students' films in one of the main community spaces in the region, an additional motivational factor for their work and for achieving the project's pedagogical and sociocultural goals.

For each one of the sessions, we prepared lesson plans describing content, exercises, resources, methods and objectives, as well as the time assigned to each part of the lesson (see Table 2 for an example). The intention was to bring film tutors and ESW teachers closer in terms of the awareness of the work to be done with the students and the kind of pedagogical strategies to be used (what, why and how). Furthermore, these documents allowed us to standardize the work done by each film tutor in each class, as they had the same 'script' for sessions happening simultaneously in different rooms.

Prior to the outset of the sessions with the students, a website was created to host the contents addressed in each class. All slides, images, short films, texts and documents used during the sessions were published weekly, and were thus made permanently available for consultation by teachers and students. The objective was to address the issue of the limited face-to-face contact with tutors through a permanent and updated support for OPL's work, available in both curricular and extra-curricular settings. The website was protected with a password made available only to the project's participants, in order to safeguard the specificity of the work and the privacy of some of the shared information. This strategy proved to be useful across the whole project (and even after its conclusion), as several students - and teachers - showed great interest in retrieving the contents and materials showed in class to consolidate knowledge, support activities and inspire their creativity and film production.

What follows is a detailed description of the contents and methods used in each of the 16 sessions, analysed in terms of the response given by the students and the results achieved.

\section{Week 1: Presentation: Introduction to film practice}

The film tutors began by presenting OPL's goals and programme, while also ascertaining the students' expectations and motivation. Many of the students seemed somewhat suspicious, not knowing exactly what would be required from them in terms of workload and effort. Others displayed excitement at the chance to work on a film project of their own during the whole semester and to experiment with something totally new. In order to clarify OPL's scope, we specified what the film production process consisted of, anticipating the students' future work on their projects. We explored topics such as: (1) differentiating between short and feature film formats; (2) defining and hierarchizing the principal film crafts (reflecting the roles that students came to assume in their collective work of film-making: producer, director, screenwriter, 


\begin{tabular}{|c|c|c|c|c|c|c|c|}
\hline$\stackrel{\xi}{=}$ & $\stackrel{0}{\circ}$ & $\grave{\sim}$ & $\stackrel{0}{\circ}$ & ì & ঐे & $\therefore$ & \\
\hline 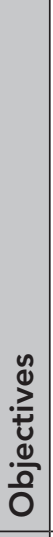 & 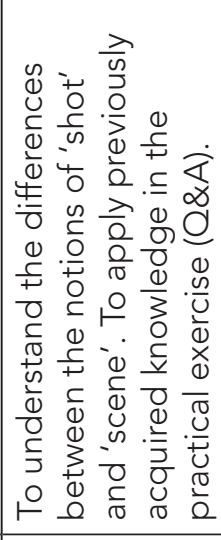 & 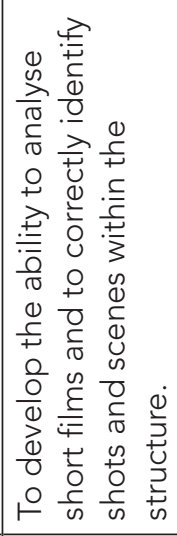 & 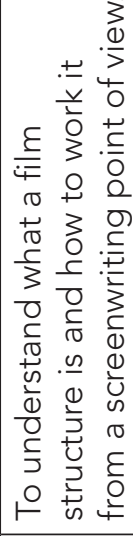 & 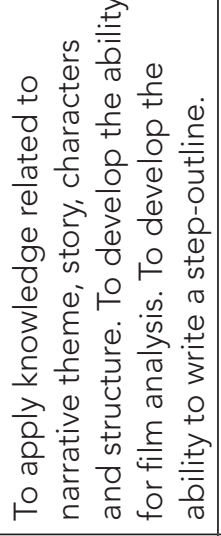 & 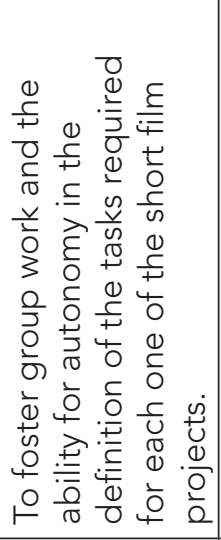 & & $\begin{array}{l}\frac{0}{0} \\
0 \\
1 \\
\frac{1}{u} \\
\frac{\pi}{0} \\
0 \\
0 \\
F \\
F \\
0 \\
\frac{0}{\sigma} \\
\infty\end{array}$ \\
\hline 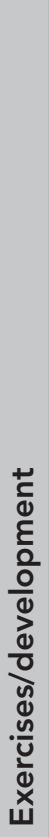 & 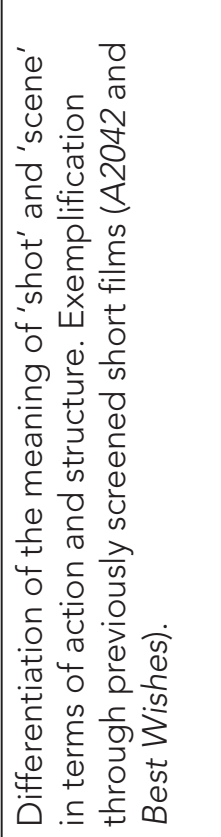 & 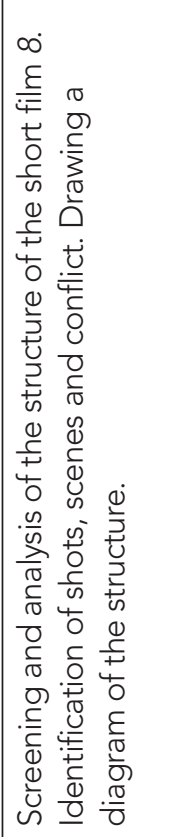 & 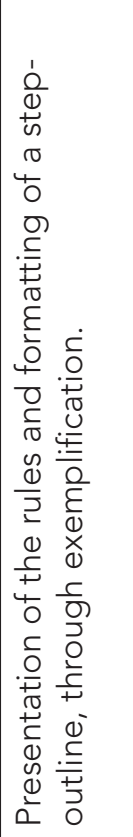 & 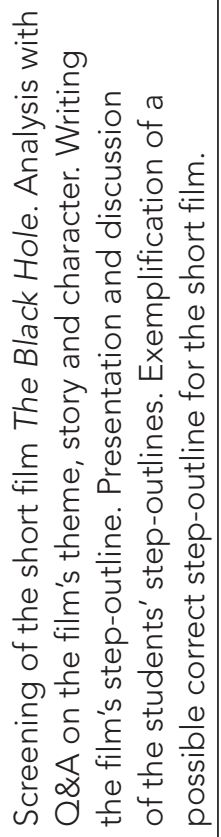 & 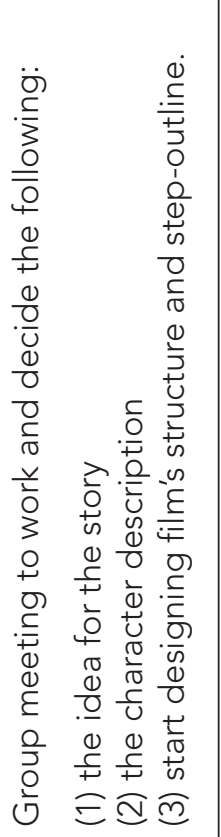 & 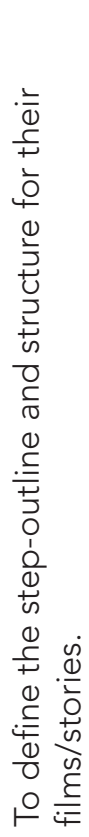 & 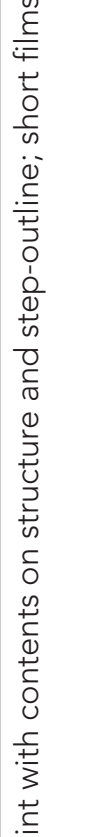 \\
\hline 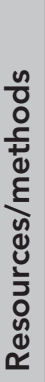 & 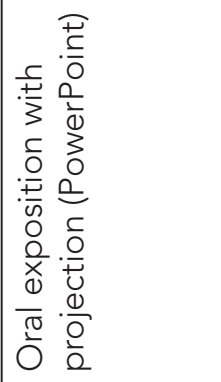 & 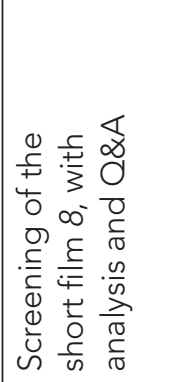 & 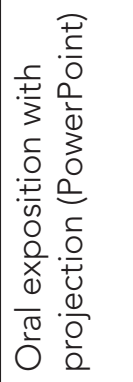 & 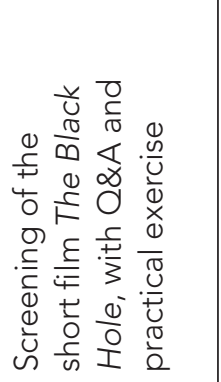 & 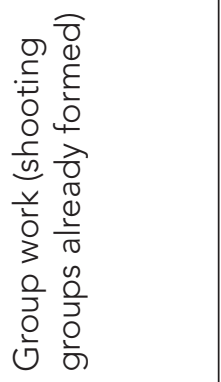 & 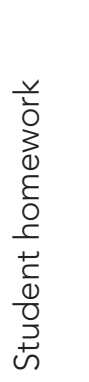 & 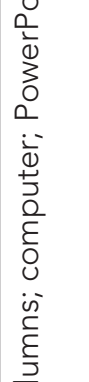 \\
\hline 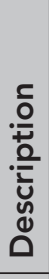 & 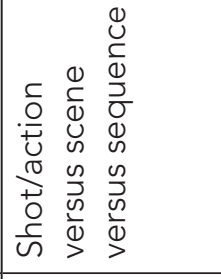 & 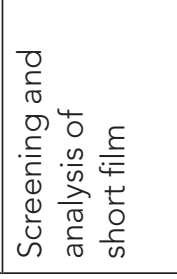 & 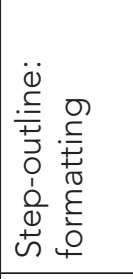 & 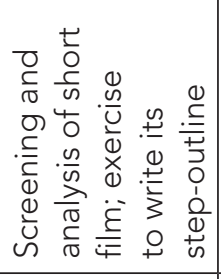 & 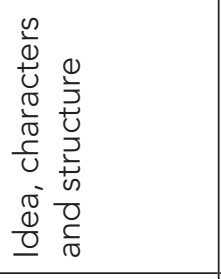 & 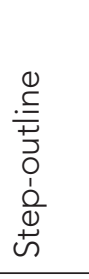 & 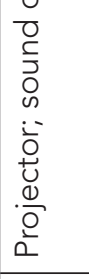 \\
\hline 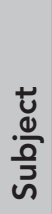 & 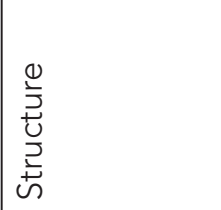 & & 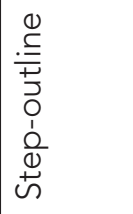 & & $\begin{array}{l}\frac{2}{\vdots} \\
\vdots \\
\frac{0}{3} \\
0 \\
0 \\
0\end{array}$ & 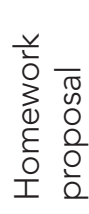 & 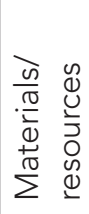 \\
\hline
\end{tabular}


director of photography, sound design, production design, editing); and (3) the main values inherent in any film shoot (solidarity, commitment, responsibility, organization, concentration, among others). In order to illustrate this content, a short film and a 'making-of' film were screened and discussed with the students. The excitement began to spread in response to these activities, and the more suspicious students (with a few exceptions) slowly came to engage in the discussion. For the following week, students were asked to bring a news article and/or an object that inspired them to create a story, and to form work groups (of five or six students) and decide upon their roles.

\section{Week 2: Concepts of film narrative}

This session aimed to show students the fundamental concepts of film narration, and to encourage their interaction with them. First, concepts of story and discourse were identified, which led to an analysis of different narrative typologies, such as space (interior/exterior), time (synchronic/anachronic), characters (external/internal features), visual composition (different shot scales and angles, depth-of-field and camera movements), and sound (diegetic/non-diegetic). Due to the students' understandable lack of knowledge regarding the theory and processes of film, certain concepts proved difficult to apprehend for some, especially the few who had seemed to show little interest in the subject. Further, it soon became apparent to us that teaching film theory to these students (concepts that they had never heard about before) would only work if combined with very specific examples and practice-based resources (otherwise, they would quickly lose interest in the session). Predicting this problem, film clips and images were used to illustrate each typology and to gauge the students' understanding of the content. At the end, a short film was shown, and its narrative components were identified by the students, who then discussed the possible reasons for their use. As the session ended, the members of each group and the roles assigned to each student were determined, and the news articles and objects brought to class were discussed.

\section{Week 3: Narrative idea and characters}

In the third session with the students, we continued to explore film narrative concepts. The short film seen in the previous session and another screened in this third session were used to discuss the themes of the stories and how they were expressed. These films were also used to introduce character development and analysis (external characterization, personality and internal traits, conflict, backstory and so on). Accordingly, small exercises and the visualization of two film excerpts were proposed for analysing characters' actions and dialogues, observing the concordant or contradictory connection between what characters in a film say and do. At the end of the session, a final short film was screened so that students could analyse and discuss all the narrative contents addressed (theme, story, and characters' features). Beginning these discussions at the end of the early sessions of the programme was not always easy. Even though students proved able to understand a story, a theme and a character, some felt uncomfortable talking in public perhaps fearing failure or that they might be ridiculed by their colleagues. Used to a practice of right and wrong answers with little leeway, the notion of 'no wrong answers' when analysing a story and a film did not seem easy to comprehend for some. It took time to earn the trust of some of the students who were not comfortable in formal education settings. However, once they realized that their ideas were, in fact, being valued and listened to, we found that these students too started to loosen up and engage in the discussion more. For Week 
4, students were asked to define the story they wanted to work with, its theme and a first description of their main characters.

\section{Week 4: Film structure and step-outline}

The fourth session addressed narrative structure, beginning with the difference between shots, scenes and sequences. One of the short films seen in the previous session and a new short film were analysed, and students were asked to apply such concepts correctly. This session also explored knowledge and skills related to the writing and analysis of step-outlines (a document used in screenwriting to briefly describe, step by step, what is most important in each scene of a film). In the last part of the session, and in order to verify these knowledge and skills (along with those covered in previous sessions), a final short film was screened: students discussed and analysed the film's theme, characters and structure, and also practised writing a step-outline for its narrative. In this session, certain students who had been quieter and seemingly more hesitant to contribute in previous sessions seemed to have a breakthrough and to trust the tutors, the teachers and their peers enough to start sharing their thoughts and ideas more. As a homework assignment, students were asked to finish defining the idea (theme/story) and characters of their film, and also to write a first version of its step-outline.

\section{Weeks 5 and 6: Screenwriting}

These sessions helped students to develop their ability to write film screenplays. In Week 5, the step-outline concepts were reiterated to compare and differentiate this format from that of a script. Excerpts from film screenplays were presented and discussed in order to identify good practices and frequent errors in the writing process. To increase the ease and speed of the screenwriting process, the free online software CeltX was presented to the students, and its use was explained all the way from initial registration to the creation of a document and use of its main tools. By the end of this part of the session, students were asked to start writing the script for their stories. We noticed that some students seemed to have trouble with this. First, it seemed more difficult for them to write a step-outline and a script of their own than to analyse one that was already written. In fact, several concepts and ideas that students seemed to have understood in theory (such as the definitions of scene and sequence, and the 'show, don't tell' practice) were not always applied successfully in their own projects. Second, although most groups developed their ideas and stories eagerly and freely, a few groups had trouble finding a story and working together. Some members of these groups seemed uninterested and/or uninspired, turning the creative process into a much more strenuous one. The tutors had to work more closely with these few groups in order to engage them with the task at hand, give them tools to come together as a group, and, in the end, be able to develop their stories. Further, and related to the few students who remained disengaged, some teachers had trouble working as facilitators, and particularly with not interfering with the students' ideas and creative processes. Nonetheless, in the end, each group of students was able to develop a workable script. This work was completed outside school hours and emailed to tutors during the following week. After reading the first versions of the screenplays, the tutors used the sixth session to analyse and discuss each script with the group who had written it, pointing out the corrections and revisions necessary for rewriting and finalizing the screenplay of each project (see Figure 2). 


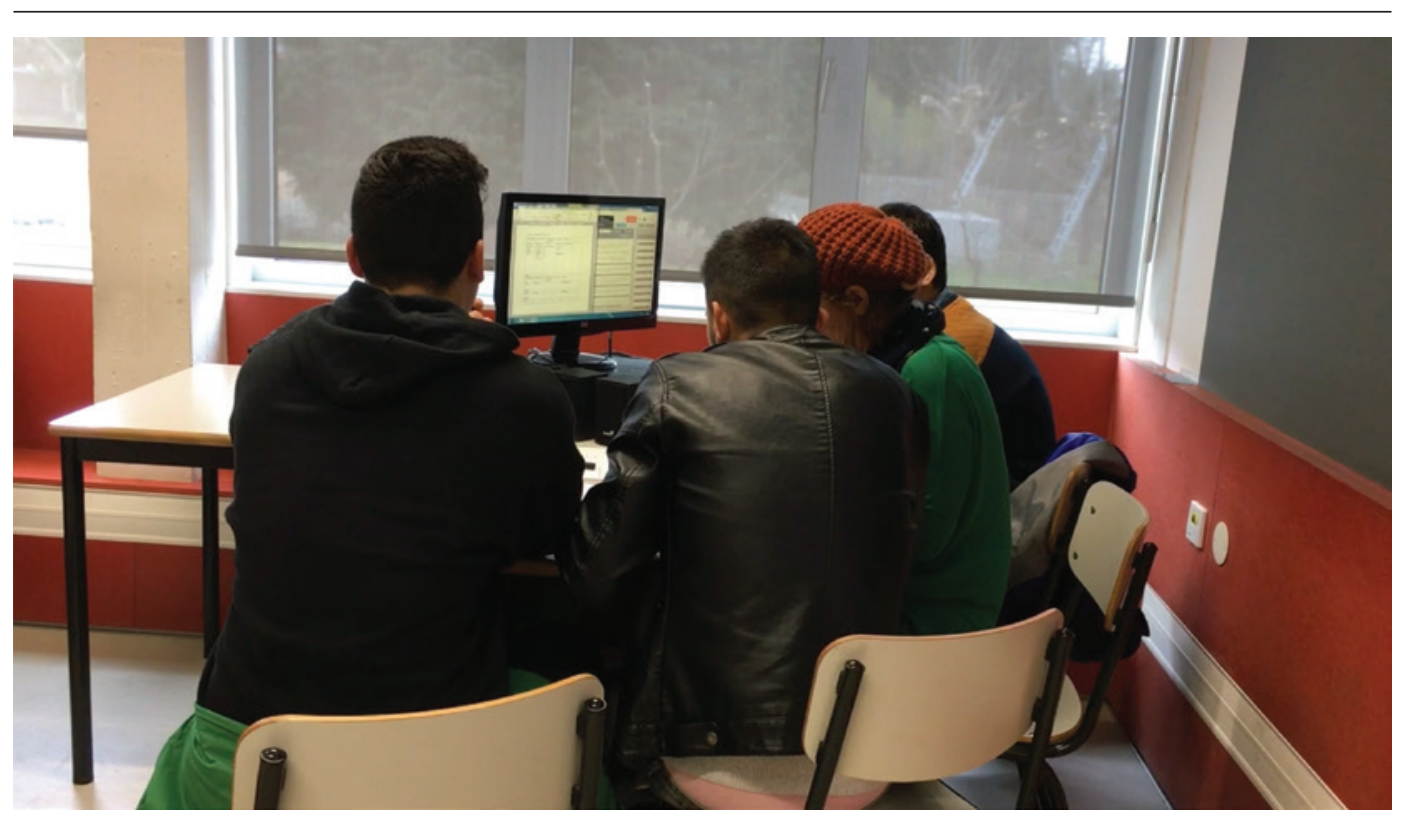

Figure 2: A group of students revising their screenplay

\section{Week 7: Pre-production}

With each group's final short film script completed, pre-production processes were addressed in the seventh session (see Figure 3). Students were shown how to perform a script breakdown and how to reorganize the gathered information in breakdown sheets. The processes of location scouting (discovering and choosing the spaces to be used in the film) and casting of actors and actresses (along with consent forms to be signed by them or their parents) were also discussed. Furthermore, students were shown how to prepare a shooting script. In the time remaining, students were given the opportunity to work in groups on these processes and to organize themselves in the best way possible to complete this work outside available school hours. The goal was to lead them to draw up a list of the resources required for their short film shoots and what shots they would be filming. Most of the students were able to fulfil this goal as, evidently, they seemed to be growing more excited with the prospect of filming their project and wanted to have everything ready for it. However, we found that there were still some students who did not put enough effort into the script breakdown, seemingly thinking that it was superfluous. In our experience, we found that these more disengaged students only seemed to complete the task due to the insistence of the tutors and teachers.

\section{Week 8: Image, lighting and sound}

The eighth session focused on image, lighting and sound recommendations for a film shoot. The aim was to exercise students' abilities to anticipate the final processes of filming and editing different fragments (shots) together. Thus, several aspects of content were addressed, such as: (1) how to identify each film shot (in a clapper or a blank sheet) for subsequent cataloguing and usage in the process of film editing; (2) the recording of open and closed shots of the same action and accomplishing at least two good takes for each shot; (3) considering the $180^{\circ}$ rule and issues regarding continuity between different shots; (4) learning how to light a scene with three-point lighting; (5) understanding how to capture the sound of a scene (synchrony with image) and the possibilities for sound design in post-production (narration, effects and music); 


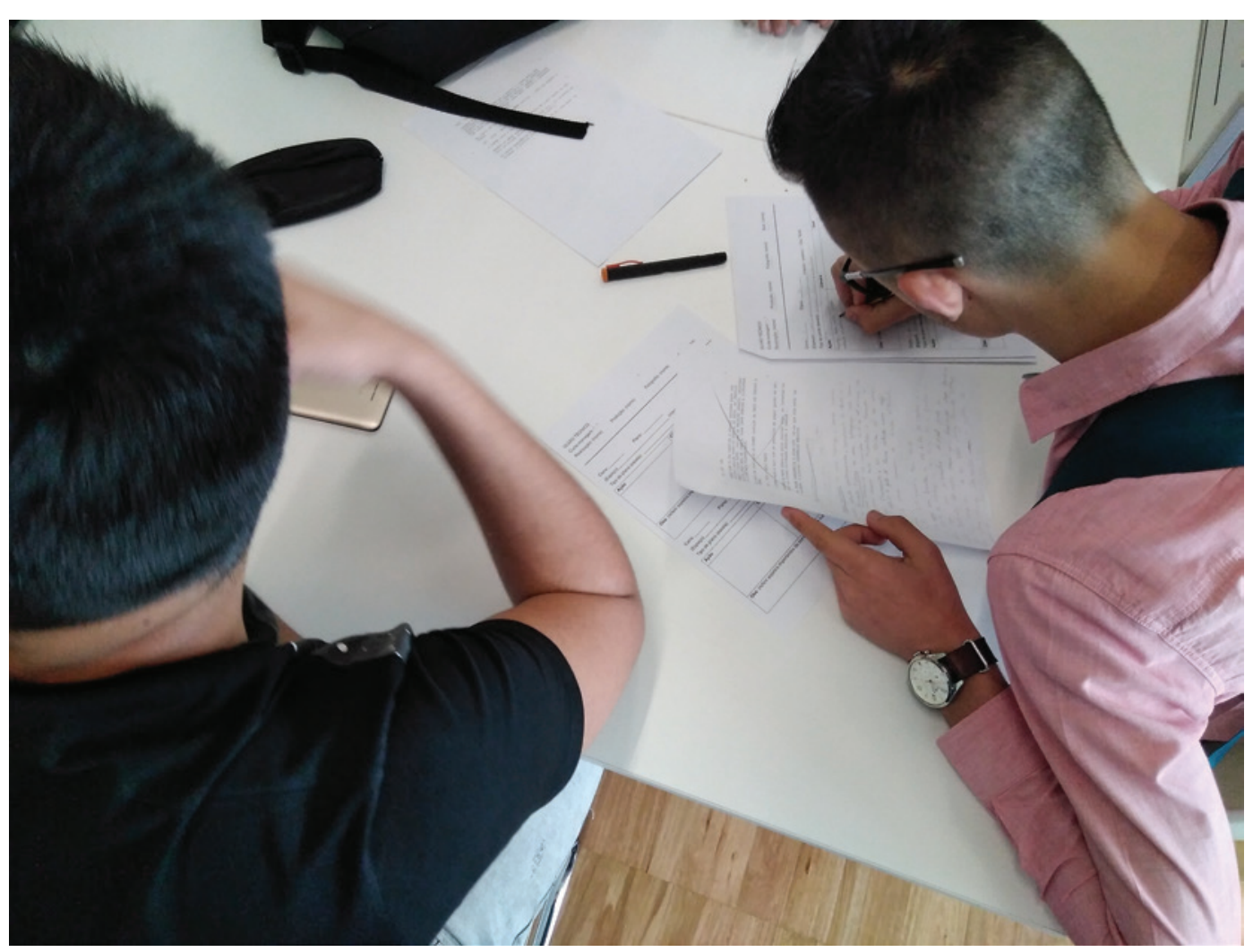

Figure 3: Students working on pre-production of their short films

(6) different movements and composition scales to consider while deciding how to shoot a given scene; and (7) how to shoot with mobile phones, anticipating students choices or need to film with greater freedom of space (outside school) and time (outside school hours). Each of these aspects of content was exemplified with film clips and audiovisual resources, and, at the end of the session, there was still time to discuss doubts, and decisions to be made, about each of the teams' projects.

\section{Week 9: Film production exercise}

In order to apply the skills acquired in the previous sessions, and to anticipate difficulties and challenges associated with film shooting, this session proposed, for each class, the collective production of a short film. Using a one-page script written by the tutors, this exercise allowed students to rehearse several processes and decisions, such as: which shots to be filmed; how/where to position the camera and how/where to capture sound; where to position and how to direct the actors; which scenery, props and wardrobe to use; repetition of less successful takes; anticipating different shot combinations (editing); and keeping an awareness of continuity. Students were assigned the roles undertaken in their own projects, so that they would become familiarized with their own tasks and responsibilities. The exercise proved to be extremely useful for students to understand and apply the knowledge and skills required for their short film production. Furthermore, even students who had appeared to be more fearful about the process of film-making and the sessions were fully engaged in the shooting of this short film. Almost every student participated in an active and enthusiastic way in this exercise (as actors, extras, camera-operators, directors and so on), showing great excitement about this experience of the more practical experimentation involved in film production (see Figure 4). 


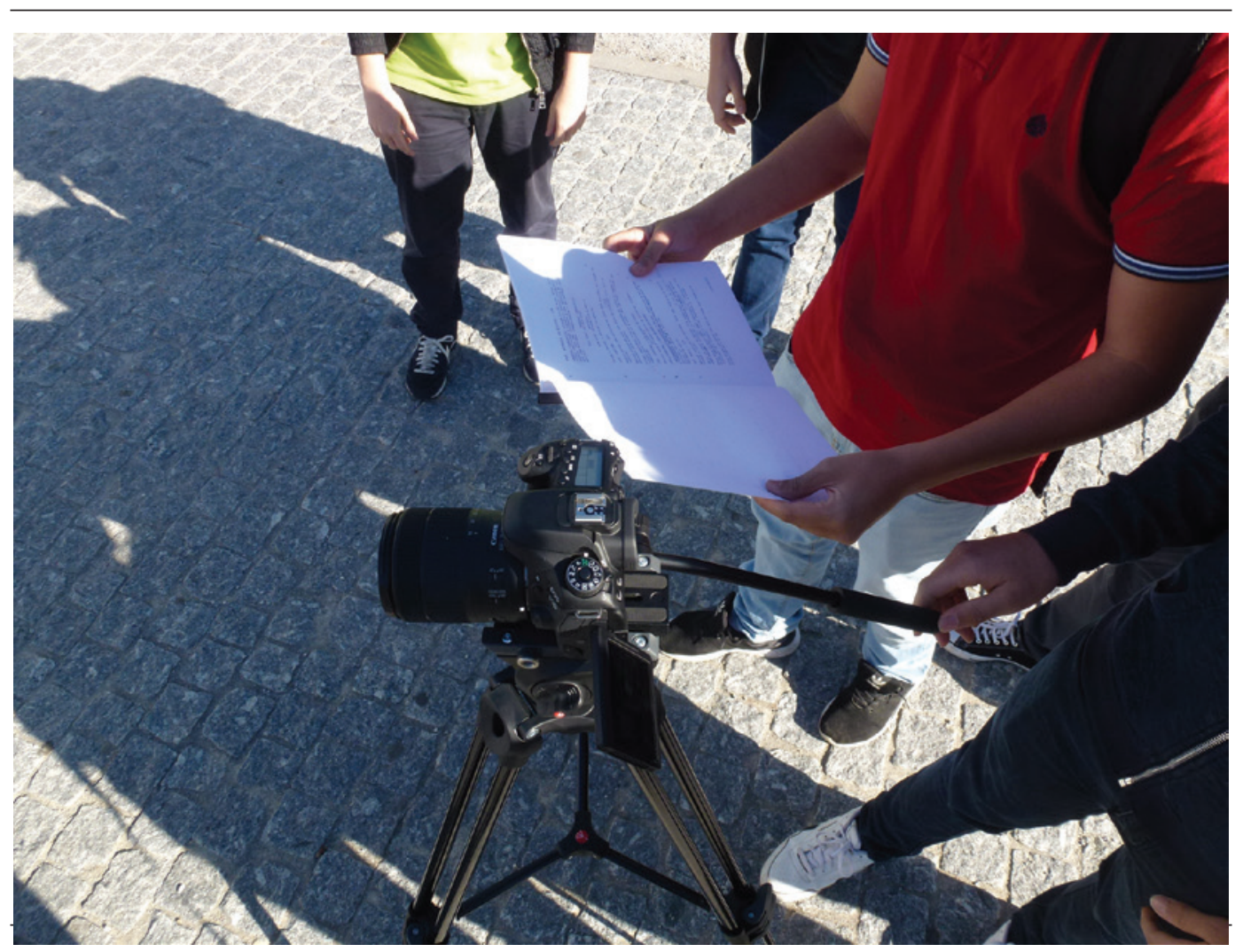

Figure 4: Students shooting a scene

\section{Week 10: Image and sound tests; closing pre-production}

In the tenth session, every aspect of the equipment acquired for the project was demonstrated: cameras, lenses, tripods, sliders, lighting kits and microphones. This created a small frenzy in class, with every student wanting to touch and try the equipment. The tutors demonstrated the various possibilities for using the equipment, and requested the participation of students while handling it. Students were shown how to assemble and prepare image and sound equipment, the differences between lenses, different focus and depth-of-field possibilities, optical movements (zoom in and out), camera/tripod movements (panoramic and tilt), and scene lighting, among other things. It was interesting to see how students helped each other when handling and trying the equipment, and how students would explain to their colleagues concepts and features that the others had not fully understood yet. At the end of the session, there was still time for tutors to sit with each group and evaluate pre-production, ascertaining any final needs and decisions to be made before beginning shooting.

\section{Weeks 11 to 13: Film shooting}

During Weeks 11, 12 and 13, each group of students had a 90-minute schedule to use the equipment for shooting their short film. ESVV teachers and tutors drew a shooting schedule (see Table 3) in order to accompany and assist students' project shooting inside and outside the school. Several students were able to accomplish their projects within this time frame, while others had to resort to additional school hours (arranged with ESV teaching staff) or extra-curricular periods (using their own mobile phones or cameras) to finish their short film production. We found that some of the 


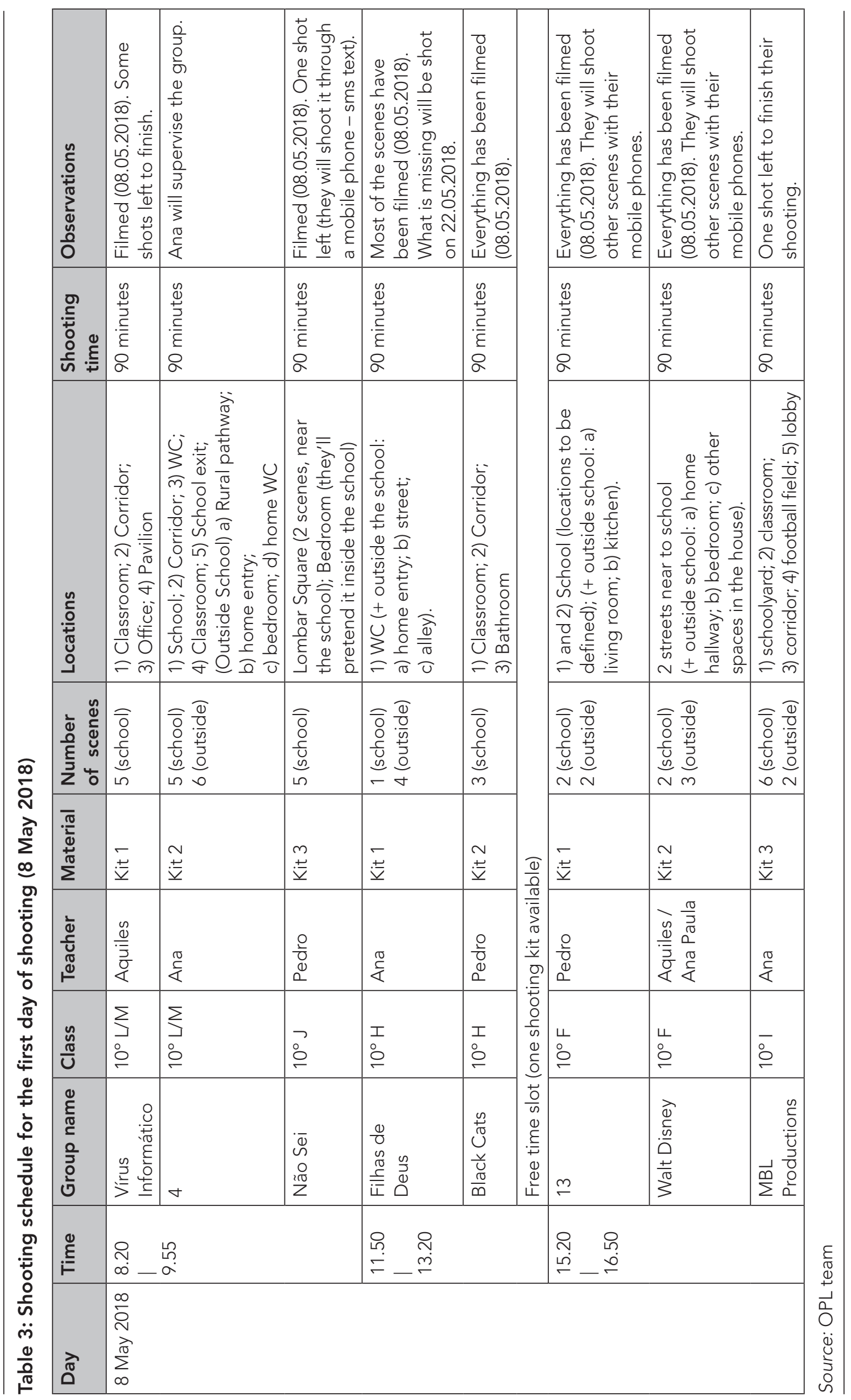


reasons why certain groups were not able to complete their work successfully within school hours were: the lack of a good script breakdown; problems with organizational skills within the group; the fact that some students forgot their worksheets on filming day; and certain students not performing their tasks within the group with sufficient consideration. During these weeks, certain students had difficulties approaching their responsibilities within the group with sufficient maturity, and tensions and struggles naturally arose during the shooting of several projects. At the same time, however, we found that most of the students rose to the occasion, working together through these difficulties and their differences, to solve the problems they encountered. Even the groups who had to deal with members of their team who remained disengaged found a way to make things work, as other students would take the reins and steer the project, gaining more responsibility, maturity and confidence in the process. Despite these struggles and the constraints that they faced, students were able to complete their shooting by the end of these three weeks.

\section{Weeks 12 to 15: Film editing}

While students were initially expected to have access to a computer and editing software, the delay in the arrival of this equipment and the time constraints of the project meant that there was insufficient time to teach students all the various tools and possibilities of film editing, leaving tutors to take over the technical editing of the films on their own computers. We tried to surpass this limitation by asking each group to produce an editing script that reflected their autonomous decisions on how they wished their films to be edited. Hence, tutors merely executed each team's decisions on which shots to use, the 'in' and 'out' timecodes for each selected shot and their order, what live sounds and visual/sound effects and music to include, which transitions to apply between shots, and what the final credits of the film were. In this way, students' responsibility and autonomy in editing their films were partially adhered to.

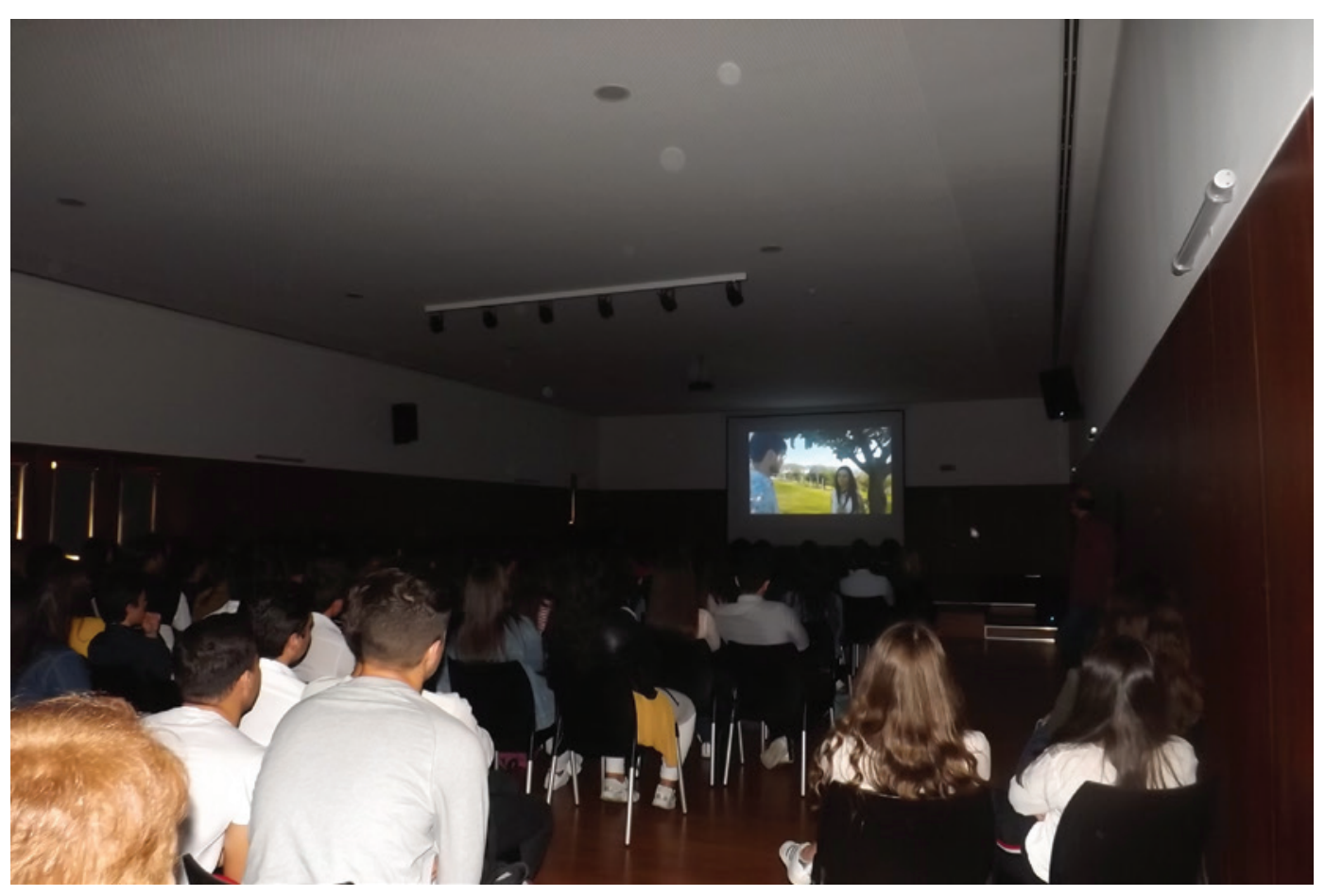

Figure 5: Students' final presentation 


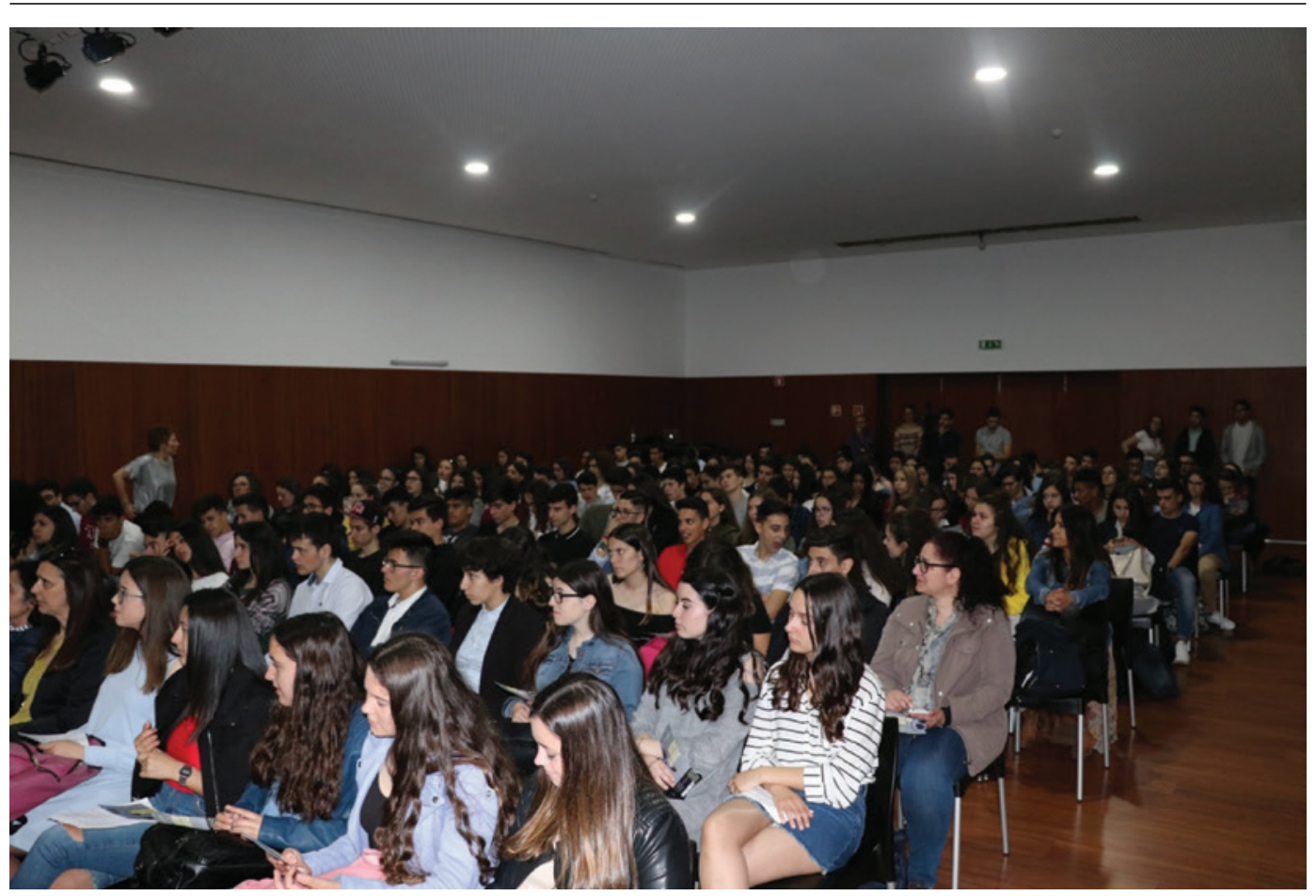

Figure 6: OPL's final presentation at the Vila Verde's Centre for Arts and Culture

\section{Week 16: Short film presentation at Vila Verde's Centre for Arts and Culture}

In the final week, students presented their short films in one of the main local cultural venues (see Figure 5 and Figure 6). Despite the primacy given to the process over the final product, the aim was to provide students with a significant moment of personal, social, cultural and educational accomplishment. These screenings presented an opportunity to recognize the effort and dedication the students had put into their films, thus positively reinforcing the capabilities they had developed and demonstrated during their process of cinematographic creation. Students were very enthusiastic about this opportunity to present their work, inviting friends and family to attend and participating in the decoration of the venue as a major film event.

\section{Discussion and conclusions}

The methodology and results of OPL provide us with a certain amount of evidence with which to reflect upon film's educational essence and relevance. Across the project's development, most students showed great enthusiasm and the capacity to integrate themselves in working groups, assuming specific roles and responsibilities in their short film production. All groups were able to produce a short film, from beginning to end, finding solutions to most of the challenges and problems that arose before, during and after their film shooting. OPL allowed the democratization of the roles previously assigned to students, which favoured not only the students themselves (through film production, students found opportunities to work around learning, concentration, behavioural, social and/or communicative difficulties), but also their teachers (who became able to foresee new ways of 'reaching' certain students beyond what were previously regarded as unsurmountable limitations). 
The 26 short films produced by the students addressed subjects such as struggles with love and relationships (7), drug addiction (6), bullying (5), depression (3), sexual violence or harassment (3), privacy (3), and altruism and friendship (3). Film productions thus allowed students to address matters that may not otherwise have found a vehicle of expression and may have been left unsaid, generating a cinematic common ground for dialogue and reflection about these themes. The students used the safe distance from reality afforded by fiction and narratives as vehicles for addressing questions and challenges directly or indirectly related to their own rational, emotional and empirical understandings of themselves, of others and of their world.

Out of the 26 narratives, 22 were shot (totally or partially) inside the school premises. This was partly because this facilitated the production of the films (which had to be filmed in a short period of time), and because it was a condition for students' use of OPL equipment (it had to be used under teacher or tutor supervision). However, students were not obliged to create stories to be filmed inside the school premises, so the fact that they did so demonstrated the will of many students to reflect on situations and struggles specific to their school context. The short films they produced can thus be seen to highlight different negotiations between young people and the school environment, and as attempts to pose questions and find answers in the tensions existing between the two. Four of the films have been uploaded to the Portuguese film education platform Primeiro Plano, and can be accessed at https://primeiroplano. ciac.pt/projeto/olhar-pela-lente/.

Despite these positive aspects of OPL's implementation, there were other aspects that proved less successful in terms of the project's efficiency. The limited contact time between film tutors and students did not allow for solid and permanent guidance about students' activities (which often had to take place outside the assigned weekly OPL hours). Also, the fact that some classes had more than 40 students limited the quality of feedback that each tutor was able to provide about each of the decisions and the questions of each project. Observation of students' work was similarly compromised by the huge disparity between the number of students (160) and groups (26), and the number of teachers (5) and film tutors (2). Moreover, the lack of permanent tutorial presence and guidance for each group led some students to lean too much on the efforts of other members of their group, relying too heavily on the contributions of more active members of the group.

We also found that students' lack of experience in practical film-making made them underestimate the need for preparation (script, storyboard, technical script, location scouting, casting) and led to them moving too quickly or too loosely on to shooting their films. Some frustration emerged among the students when difficulties started to arise, and insufficient degrees of preparation became noticeable in their struggle to respond to challenges inherent within film production. Nevertheless, and as previously mentioned, students were able to deal with these struggles and frustrations and find (or accept) solutions for them, an experience that may well prove highly positive and transferable to future projects with a similar scope. However - and this mostly pertains to the stages of screenwriting and narrative creation - teachers were sometimes tempted to solve these struggles and difficulties, overstepping students' creative freedom and compromising their autonomy in problem-solving and decision-making. In our opinion, this was due to the excitement and motivation that the project also generated in teachers (which should be seen as a positive aspect in certain respects), and to the short period of time available for students to find solutions to their problems and struggles. (We found that teachers sometimes prevented students 
from taking more time to reflect upon certain problems and decisions because of the limited time frame.) As acknowledged below, the difficulties that emerged from limited contact time and the often demanding nature of film production are aspects of the project that we ourselves, as film education practitioners leading the delivery of the project, must take responsibility for, and cannot be blamed on the students and teachers who participated in it.

In 2019, ESVV conducted a survey of 30 of the 160 students involved in OPL, with the intention of obtaining quantitative and qualitative feedback from them about the project. The results, which have not yet been published or disclosed, show that the impact of OPL on students' motivation and school results came mostly from an increase in their knowledge and vocabulary on film content (film literacy) and the possibility of developing a practical project (short film production). Nevertheless, the results of the survey also confirm some of the weaknesses mentioned above, such as students who struggled with group disorganization and team members who felt alienated from the project, while also dealing with the challenges of preparing and shooting a short film in a limited amount of time. We believe that future applications of the project's methodology should take into account these weaknesses and constraints in order to mediate them and improve the project's implementation and impact. The methodology would probably work better if implemented with a greater amount of face-to-face contact each week. It would also benefit from a smaller ratio between the number of students and the numbers of teachers and tutors, as well as from fewer students and groups per class and working hour. These changes would probably allow closer observation and guidance of the particularities of each project, answering more of students' questions and clarifying procedures in their process of film production.

Two further considerations may also increase the future effectiveness of the methodology. First, it would be beneficial to ensure the resources and time required to enable students to experience a more autonomous process of film editing. Handling the tools and software programs of film editing is fundamental for a holistic understanding of film narratives, and for the ability to solve the creative challenges inherent in the film-making process. Second, diversifying the roles adopted by students in different projects could mean a broader and transversal understanding of the responsibilities and processes of each craft. In this project, due to the small size of the groups, each student helped and collaborated with colleagues in the exercise of various functions, but applying these skills in different projects would expand the challenges encountered, and enhance the solutions found.

Despite such criticisms, and bearing in mind once again the British Film Institute's recommendations for film production within school contexts, OPL facilitated the development of several desirable abilities in ESW students: to participate constructively in the creative process; to be aware of expressive and creative choices in image, sound and sequence production; to use different technical resources; to be aware of the roles of each team member; and to understand and integrate different stages and processes of film production (BFI, 2015: 15). The project also contributed to the acquisition and/ or development of capabilities that went beyond the limited scope of cinematographic creation, such as teamwork, communication and expressive abilities, decision-making, commitment, time and resource management, creativity, problem-solving, working under pressure, and being responsible for an assigned task (BFI, 2015: 26).

$\mathrm{OPL}$ also instructed almost 160 students from non-artistic backgrounds in the production of 26 short fictional films. Young people for whom film history was something alien and different became aware of, and knowledgeable about, film language and the processes and stages inherent in film production. They integrated their idiosyncratic 
desires and peculiarities into a collective effort for the purpose of achieving a final result matching their expectations and ambitions. Looking at the objectives initially defined by the project, OPL was able to stimulate active reflection and participation in film reception and production, with new literacy tools, a heightened technical and aesthetic sensibility, and critical thinking skills sharpened by the creative criteria followed during the production of students' short films. The project also offered potential for improving the students' behavioural, motivational and cultural outlook.

OPL demonstrates that the school is an important meeting place between young people and film. By providing the necessary guidance and resources to create opportunities for practical film-making, the school here is a catalyst for personal and collective student growth, fostering skills and knowledge that position students as better informed, integrated and active citizens. Furthermore, students' experiences on this project have contributed to the nurturing of capabilities that move beyond the classroom and into their personal and social lives, reinforcing the school as the key locus of the individual's education into adult life. We therefore conclude that it is important to motivate young people to be interested in cinema, to discover what it is, what it means to make films, and what we can think, feel, express and live through them. Any spark of interest we might ignite in a student's way of thinking or feeling through film experiences within school environments will be a step forward in the effort to secure cinema's place at the forefront of our education and culture.

\section{Acknowledgment}

This paper is sponsored by national funds through the Foundation for Science and Technology (FCT) under the project reference UIDB/00622/2020.

\section{Notes on the contributors}

Pedro Alves is an invited assistant professor at the School of Arts, Catholic University of Portugal, Porto, and a researcher at the Research Centre for Science and Technology of the Arts (CITAR). He holds a PhD in audiovisual communication from the Complutense University of Madrid. He has participated in several conferences, and has published works on film theory, practice and education. He also collaborates with UNESCO as an expert for project-based activities, and works regularly with schools on film-related projects and events.

Ana Sofia Pereira recently completed her PhD on 'Women Screenwriters: A dynamic definition of language in the feminine in Portuguese cinema'. As well as her work as a researcher and lecturer at several universities in Portugal and other countries, she is a screenwriter and script supervisor. Her recent work includes a television series for which she was co-writer and script supervisor, which premiered early in 2019 on one of Portugal's major networks, RTP1.

\section{References}

Aidelman, N. and Colell, L. (2018) 'Transmitting cinema: Some proposals for our time'. Film Education Journal, 1 (2), 147-62. Online. https://doi.org/10.18546/FEJ.01.2.04 (accessed 13 May 2020).

Alves, P.M.B. (2015) 'La ficción "realizada": Implicaciones y transferencias entre ficción y realidad en la pragmática del cine narrativo'. PhD thesis, Universidad Complutense de Madrid.

Babo, I. (2015) Espectadores e públicos activos. Lisbon: Nova Vega. 
Baptista Neves, P.J.F. (2013) 'Construção de recursos didáticos para a opção artística de cinema no $3^{\circ}$ ciclo do ensino básico'. In Baptista, T. and Martins, A. (eds) Atas do II Encontro Anual da AIM. Lisbon: Associação de Investigadores da Imagem em Movimento, 649-62. Online. http://aim. org.pt/atas/Atas-IIEncontroAnualAIM.pdf (accessed 18 February 2020).

Bergala, A. (2007) La hipótesis del cine: Pequeño tratado sobre la transmisión del cine en la escuela y fuera de ella. Barcelona: Laertes.

BFI (British Film Institute) (2011) Screening Literacy: Case studies. London: British Film Institute. Online. https://ec.europa.eu/assets/eac/culture/library/studies/literacy-case-studies_en.pdf (accessed 22 March 2020).

BFI (British Film Institute) (2015) A Framework for Film Education. London: British Film Institute. Online. https://tinyurl.com/yex2qy3v (accessed 13 February 2020).

ESV (Escola Secundária de Vila Verde) (2016) Projeto Educativo 2016-2019. Vila Verde: Escola Secundária de Vila Verde. Online. https://tinyurl.com/sslsnsz (accessed 18 February 2020).

ESV (Escola Secundária de Vila Verde) (2017) 'Olhar pela Lente'. Online. https://esvv.edu.pt/ projetos/olhar-pela-lente/ (accessed 18 February 2020).

García Amilburu, M. and Landeros Cervantes, B. (2011) Teoría y práctica del análisis pedagógico del cine. Madrid: Universidad Nacional de Educación a Distancia.

García García, F. and Rajas, M. (2011) 'El relato: Una aproximación interdisciplinar'. In García García, F. and Rajas, M. (eds) Narrativas Audiovisuales: El relato. Madrid: ICONO14, 9-12.

Gispert Pellicer, E. (2009) Cine, ficción y educación. Barcelona: Laertes.

Lardoux, X. (2014) 'For a European film education policy'. Online. https://tinyurl.com/t3tjtzv (accessed 22 March 2020).

Lazo, C.M. and Gabelas Barroso, J.A. (2012) 'La creación de un cortometraje como metáfora de la educación mediática: Dimensión lúdica y social de la producción'. Revista ICONO14, 10 (1), 41-60. Online. https://doi.org/10.7195/ri14.v10i1.70 (accessed 13 May 2020).

Plantinga, C. (2009) Moving Viewers: American film and the spectator's experience. Berkeley: University of California Press.

Plummer, K. (2019) Narrative Power: The struggle for human value. Cambridge: Polity Press.

Reia-Baptista, V., Burn, A., Reid, M. and Cannon, M. (2014) 'Screening literacy: Reflecting on models of film education in Europe'. Revista Latina de Comunicación Social, 69, 354-67. Online. https://doi.org/10.4185/rlcs-2014-1015en (accessed 13 May 2020).

Reigada, T. (2016) Ensinar com a sétima arte: O espaço do cinema na didática da História. Porto: CITCEM/Afrontamento.

Robinson, J.A. and Hawpe, L. (1986) 'Narrative thinking as a heuristic process'. In Sarbin, T.R. (ed.) Narrative Psychology: The storied nature of human conduct. New York: Praeger, 111-25.

Rodríguez-Hoyos, C. and Manrique Solana, R. (2015) 'Perturbando mentes: El cine como herramienta de transformación personal'. Revista Interuniversitaria de Formación de Profesorado, 29 (1), 109-18.

Schank, R.C. and Berman, T.R. (2002) 'The pervasive role of stories in knowledge and action'. In Green, M.C., Strange, J.J. and Brock, T.C. (eds) Narrative Impact: Social and cognitive foundations. Mahwah, NJ: Lawrence Erlbaum Associates, 287-313.

Strange, J.J. (2002) 'How fictional tales wag real-world beliefs: Models and mechanisms of narrative influence'. In Green, M.C., Strange, J.J. and Brock, T.C. (eds) Narrative Impact: Social and cognitive foundations. Mahwah, NJ: Lawrence Erlbaum Associates, 263-86.

Vaccaro, J. and Valero, T. (2011) Nos vamos al cine: La película como medio educativo. Barcelona: Universitat de Barcelona. 